Chapter 3

\title{
Technology of Thermal Treatment
}

Cement is made of clinker and ground gypsum, whereas clinker is produced from fired limestone and clay mixed in particular percentages. Portland cement clinker was first made in 1842 in modified form of traditional static limekiln. Around 1885, the experiments began on the design of continuous kilns. One of the designs was the shaft kiln, similar in design to a blast furnace. The raw meal in the form of lumps and fuel were continuously added at the top, and clinker was continually withdrawn at the bottom. Compressed air was blown through from the base to combust the fuel. The shaft kiln had been used for only short period of time before it was forced out by the rotary kiln, but it has had a limited renaissance from 1970 onward in China and elsewhere, when it has been used for the small-scale, low-tech plants in rural areas away from transport access. A typical shaft kiln can produce 100-200 tons/day. Nowadays, rotary kiln is one of the key equipment in cement industry used to convert calcineous raw meal to cement clinker. Raw meal for the cement production is a mixture of predetermined proportions of limestone, silica, and small quantities of alumina and iron oxide [295,296].

The cement making processes are extremely energy consuming. Typically for the production of one ton of cement, a well-equipped plant consumes nearly 3 GJ. For each ton of produced clinker an equivalent amount of greenhouse gases is emitted. The manufacture of cement is the focus of considerable attention worldwide because of giant amount of used energy and high environmental impact of the process. Considering the recent impetus on the emission of greenhouse gases reductions and on the reduction of energy consumption, a renewed emphasis arises on developing the computational models for cement industry and on applying this understanding for the performance enhancement [297].

The most important plant unit in cement manufacturing is the kiln [298]. The raw material passes sequentially through pre-heater, calciner, kiln and cooler to form the cement clinker. In a pre-heater section the raw meal is pre-heated to the calcination temperature via hot gases coming from calciner. In calciner, the raw meal is partially calcined. The energy required for the endothermic calcination reaction is provided by combusting a suitable fuel. In most cases, coal is used to provide the required energy, especially in India. The calciner is supplied with tertiary air from the cooler and with air coming out of kiln exhaust. The former is to supply coal with $\mathrm{O}_{2}$ sufficiently during the combustion and the later to utilize the heat of kiln gases to enhance the calcination reaction. Hot gases from calciner are sent to pre-heater assembly to pre-heat the solids. Partially calcined solids from the calciner are fed slowly to a rotary kiln. In rotary kiln, remaining calcination and other reactions of formation of clinker phases proceed [297,299,300]. 
The energy required for the endothermic clinker reactions is provided by burning coal in the kiln. The pulverized coal along with the pre-heated air (secondary air) is fed to the kiln in a counter current mode with respect to solids. A part of solids melts in the kiln. The melt causes an internal coating on the kiln refractory. The counter current flow of gas entrains solid particles in the free board region. Such entrainment enhances the rates of radiative heat transfer by increasing effective emissivity and conductivity. Hot clinker is discharged from kiln to clinker cooler and hot gases from kiln exhaust are sent to the calciner. In clinker cooler, a part of energy of solids is recovered back by heat exchange with air. The pre-heated air from coolers is passed to kiln and calciner as secondary and tertiary air, respectively. A small part of air may be vented if required [297].

The clinker formation process by the fluidized bed kiln system was developed by Yuko at al. [301].The average size of clinker produced by this system is about $2 \mathrm{~mm}$, that is much smaller than that of a rotary kiln clinker.

\section{Thermal treatment of strontium aluminate clinker}

The synthesis of strontium aluminate clinker requires the raw material pre-treatment, the calculation of composition, the preparation of mixture of raw materials, the homogenization or granulation, the thermal treatment, the grinding and fine milling of strontium aluminate clinker. The individual steps of this process are discussed in this chapter. The scheme of production technology of clinker is schematically shown in Fig.1.

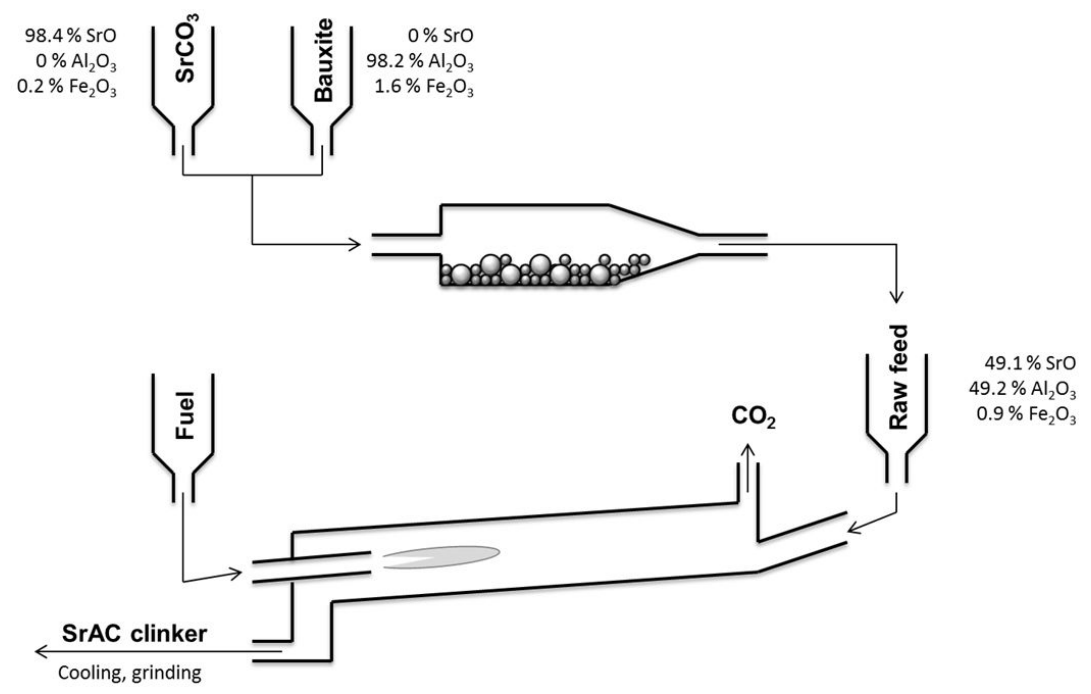

Figure 1. Scheme of clinker production technology. 
The heating rate does not play so important role during the processing of strontium aluminate clinker such as for Portland cement, where the decomposition of tricalcium silicate to dicalcium silicate and free water and the formation of $\gamma$-dicalcium silicate threaten to devalue the binding properties. On the other hand, increasing cooling rate increases the reactivity of glass phase.

The processes which take place during the thermal treatment of raw meal to strontium aluminate clinker are:

1. Drying: evaporation of free and physically bonded water and adsorbed water without the changes of chemical composition of dry mater. Drying is usually finished up to the temperature of $105 \pm 5^{\circ} \mathrm{C}$.

2. Dehydroxylation: thermal treatment of aluminium hydroxide; water is released from hydroxyl groups of mineral.

3. Thermal decomposition of strontium carbonate:

4. Formation of strontium aluminate and the establishment of equilibrium composition.

5. Sintering of solid phase.

6. Formation of melt and sintering of liquid phase.

7. Cooling of clinker.

\section{Drying}

Drying is the technological process, which removes water from treated material by evaporation. Therefore, the reduction of material moisture does not usually relate to the significant changes in mineralogical composition, the raw material is often considered as the twocomponent mixture of dry mater and water.

In the dryer, water evaporates from material to flow of air, but the amount of water that can be absorbed by gas phase depends on the conditions of drying process. If the gas phase is supersaturated by water at given temperature, the moisture of material does not decrease any more. Therefore, the drying process must respect certain physical regularities.

There is certain value of maximum amount of water that can be absorbed by air at constant temperature and pressure. Therefore, three parameters are necessary for the characterization of the state of air:

- Temperature $(T)$ : the maximum amount of water that can be absorbed by gas phase increases with temperature.

- Pressure $(P)$;

- Moisture: can be characterized by several ways which are described below.

- To specify the content of water in air the following parameters can be used: 
- Partial pressure of water vapor in air $\left(P_{\mathrm{D}}[\mathrm{Pa}]\right)$.

- Absolute air humidity $\left(W_{\mathrm{A}}\left[\mathrm{kg} \bullet \mathrm{m}^{-3}\right]\right)$ is defined as the weight of water vapour per cubic meter of air.

- Relative air humidity $\left(W_{\mathrm{R}}\right)$ is defined as the dimensionless ratio of parameters mentioned above for actual state of air $\left(P_{\mathrm{D}}\right.$ or $\left.W_{\mathrm{A}}\right)$ and air supper saturated by water $\left(P_{\mathrm{D}}{ }^{*}\right.$ or $\left.W_{\mathrm{A}}{ }^{*}\right)$ :

$$
W_{R}=\frac{P_{D}}{P_{D}^{*}}=\frac{W_{A}}{W_{A}^{*}}
$$

- Specific air humidity $\left(W_{\mathrm{S}}\left[\mathrm{kg}_{\mathrm{w}} \bullet \mathrm{kg}_{\mathrm{air}}{ }^{-1}\right]\right)$ is the weight of water vapours in one kilogram of dry air.

- Temperature of wet point $\left(T_{\mathrm{wp}}\right)$;

- Temperature of wet thermometer $\left(T_{\mathrm{wt}}\right)$.

The driers use the heat of drying air phase to reduce the moisture of dried material. The temperature of air decreases as water evaporates but the formed water vapor that possesses this heat becomes the part of air phase. In the other words, if the losses aren't taken into account, the enthalpy of air is constant during the drying process. The drier without the heat losses is termed theoretical drier.

Rotary dryers are commonly used to dry and process granular materials. They are applied across a wide range of industries ranging from food production to cement production. Rotary dryers contain lifters to lift the material away from the bottom of the dryer and then to drop it through the gas to promote the mass and heat transfer between the granular material and the gaseous phase [302].

\section{Firing process}

Firing process includes the technology and equipment which provide heat in order to reach the temperature necessary to achieve required phase composition and properties of the product. Ceramic and concrete technology use furnaces of different type, but it is not necessary to use the pre-calcination unit as for the preparation of strontium aluminate cement. That implies from higher thermal stability of $\mathrm{SrCO}_{3}$ when compared with $\mathrm{CaCO}_{3}$ (discussed in Chapter 4.2). This turns the attention to the technologies of heat regeneration or recuperation from gas processing.

The furnace is heated by the combustion of fuel, the components of which are oxidized according to the following exothermic reactions:

$$
\mathrm{H}_{2}+1 / 2 \mathrm{O}_{2} \rightarrow \mathrm{H}_{2} \mathrm{O} \quad\left(\Delta_{\mathrm{r}} \mathrm{H}^{\circ}=-241581 \mathrm{~kJ}\right)
$$




$$
\begin{array}{cc}
\mathrm{C}+\mathrm{O}_{2} \rightarrow \mathrm{CO}_{2} & \left(\Delta_{\mathrm{r}} \mathrm{H}^{\circ}=-393484 \mathrm{~kJ}\right) \\
\mathrm{C}+1 / 2 \mathrm{O}_{2} \rightarrow \mathrm{CO} & \left(\Delta_{\mathrm{r}} \mathrm{H}^{\circ}=-110696 \mathrm{~kJ}\right) \\
\mathrm{S}+\mathrm{O}_{2} \rightarrow \mathrm{CO}_{2} & \left(\Delta_{\mathrm{r}} \mathrm{H}^{\circ}=-296511 \mathrm{~kJ}\right)
\end{array}
$$

For these purposes, the dry air is considered as the mixture of $\sim 21$ vol. $\% \mathrm{O}_{2}$ and $\sim 79 \% \mathrm{~N}_{2}$. Therefore the $\mathrm{O}_{2}: \mathrm{N}_{2}$ and $\mathrm{O}_{2}:$ Air ratios are $21: 79=1: 3.76$ and $21: 100=1: 4.76$, respectively. Using the Avogadro law, one kmol of gaseous species under standard conditions corresponds to $22.4 \mathrm{~m}_{\mathrm{N}}{ }^{3}$ (subscript " $N$ " denotes normal condition, i.e. the temperature of $273,15 \mathrm{~K}$ and the pressure of $0.1013 \mathrm{MPa})$.

For example, according to Eq.2, 0.5 $22.4 \bullet 4.76=53.3 \mathrm{~m}_{\mathrm{N}}{ }^{3}$ of air are necessary for the combustion of $1 \mathrm{kmol}$ of $\mathrm{H}_{2} .1 \mathrm{kmol}\left(22.4 \mathrm{~m}_{\mathrm{N}}^{3}\right)$ of gaseous water is formed during this process. Air used for the oxidation contains $0.5 \bullet 22.4 \bullet 3.76=42.1 \mathrm{~m}_{\mathrm{N}}^{3}$ of inert $\mathrm{N}_{2}$ gas. The combustion process is termed as ideal, if the final product contains only $\mathrm{CO}_{2}, \mathrm{H}_{2} \mathrm{O}$ and $\mathrm{SO}_{2}$ species.

The amount of applied oxygen may be stoichiometric, higher or lower than stoichiometric. It can be described by the following dimensionless ratio:

$$
n=\frac{\text { Amount of applied air or oxygen }}{\text { Stoichiometric amount of applied air or oxygen }}
$$

Depending on this, neutral $(n \approx 1)$, oxidizing $(n>1)$ or reducing conditions $(\boldsymbol{n}<1)$ can occur in the furnace atmosphere.

The reaction enthalpy for the other species can be calculated from tabulated thermodynamic data, e.g. [303,304], or using the Kirchhoff's laws. For example, the ideal combustion of methane gas is expressed by the equation:

$$
\mathrm{CH}_{4}+\mathrm{O}_{2} \rightarrow \mathrm{CO}_{2}+2 \mathrm{H}_{2} \mathrm{O}
$$

with $\Delta_{\mathrm{r}} H^{\circ}=-802803 \mathrm{~kJ}$. Therefore, the formation of methane (Eq.8) shows the reaction enthalpy of-73 $843 \mathrm{~kJ}$ :

$$
\mathrm{C}+2 \mathrm{H}_{2}(\mathrm{~g}) \rightarrow \mathrm{CH}_{4}(\mathrm{~g})
$$

That relationship reveals that the value of $\Delta_{\mathrm{r}} H^{\circ}(\mathrm{Eq} \cdot 7)=\Delta_{\mathrm{r}} H^{\circ}(\mathrm{Eq} \cdot 3)+2 \Delta_{\mathrm{r}} H^{\circ}(\mathrm{Eq} \cdot 2)-\Delta_{\mathrm{r}} H^{\circ}(\mathrm{Eq}$. 8) $=-802803 \mathrm{~kJ}$.

Heat released by the combustion of one mol of fuel under standard conditions is termed as the heat of combustion $\left(\Delta_{\mathrm{c}} H^{\circ}\right)^{1}$. Depending on the conditions the following expressions of combustion heat apply:

1 It stands to reason that $\Delta_{\mathrm{r}} H^{\circ}=\Delta_{\mathrm{c}} H^{\circ}$ for Eqs. 2 - 5 and Eq. 7 . 
a. Higher Heating Value (HHV) or High Caloric Value (HCV): heat released during ideal combustion process performed under standard ambient conditions ${ }^{2}$. Formed products were cooled to their original temperature, i.e. the temperature before combustion. All formed water vapor condensed to liquid. For example:

$$
\mathrm{CH}_{4}(\mathrm{~g})+\mathrm{O}_{2}(\mathrm{~g}) \rightarrow \mathrm{CO}_{2}(\mathrm{~g})+2 \mathrm{H}_{2} \mathrm{O}(\mathrm{l}) \quad \mathrm{HHV}=-890564 \mathrm{~kJ} \cdot \mathrm{mol}^{-1}
$$

b. Lower Heating value (LHV), Lower Caloric Value (LCV) or Net Caloric Value (NCV): similar to HHV, but water produced by the combustion process stays in gas phase (Eq. 10). It is obvious that HHV and LHV differ in the enthalpy related to the condensation of water- $44 \mathrm{~kJ} \bullet \mathrm{mol}^{-1}$. For two mols of water the difference HHV(Eq.9) - LHV(Eq.10)=-88 $\mathrm{kJ} \bullet \mathrm{mol}^{-1}$, i.e. $\mathrm{HHV}=\mathrm{LHV}+$ latent heat of water.

$$
\mathrm{CH}_{4}(\mathrm{~g})+\mathrm{O}_{2}(\mathrm{~g}) \rightarrow \mathrm{CO}_{2}(\mathrm{~g})+2 \mathrm{H}_{2} \mathrm{O}(\mathrm{g}) \quad \mathrm{LHV}=-802556 \mathrm{~kJ} \cdot \mathrm{mol}^{-1}
$$

The bomb calorimeter is used for the determination of heating values of fuels.

The physicochemical environment of cement kilns is ideal for the co-combustion of a number of organic wastes. The economic, as well as environmental benefits are achieved by the substitution of fossil fuels, mainly coal and petcoke. Specific types of alternative fuels (AFs) derived from the mixtures of wastes, such as animal byproduct waste (ABW), agricultural plastic waste (APW), automotive waste plastics (AWP), biological sludge (BIS), cutting oil emulsions (COI), cable plastic waste (CPW), demolition waste (DW), industrial waste fuel (INBRE), refuse derived fuel (RDF or BRAM or SRF), rice husk (RH), refinery sludge (RS), spent solvents (SS), tire derived fuel (TDF), waste oils (WO), etc., are developed [305-308].

\begin{tabular}{llllll}
\hline \multirow{2}{*}{ Constituents } & \multicolumn{2}{l}{ Raw mixture } & \multirow{2}{*}{ Constituents } & \multicolumn{2}{l}{ Raw mixture after recalculation } \\
\cline { 2 - 6 } & [\%] wt. & & [g] & [\%] wt. & [\%] mol. \\
\hline $\mathrm{SrO}$ & 49.1 & $\mathrm{SrCO}_{3}$ & 70.0 & 58.3 & 49.3 \\
\hline $\mathrm{Al}_{2} \mathrm{O}_{3}$ & 49.2 & $\mathrm{Al}_{2} \mathrm{O}_{3}$ & 49.2 & 41.0 & 50.2 \\
\hline $\mathrm{Fe}_{2} \mathrm{O}_{3}$ & 0.9 & $\mathrm{Fe}_{2} \mathrm{O}_{3}$ & 0.9 & 0.7 & 0.6 \\
\hline$\Sigma$ & 99.2 & $\Sigma$ & 120.1 & 100 & 100 \\
\hline
\end{tabular}

Table 1. The composition of raw meal.

Adopting the raw material composition from Fig.1 (calculated for $\boldsymbol{M}_{\mathrm{H}}=0.98$ as was described in Chapter 2.3.1), it is possible to provide the example for calculation of material and energetic balance for the process of calcination of strontium aluminate clinker.

2 The standard temperature and pressure conditions (STP, $0^{\circ} \mathrm{C}$ and $100 \mathrm{kPa}$ ) are different from standard ambient temperature and pressure (SATP, $25^{\circ} \mathrm{C}$ and $\left.100 \mathrm{kPa}\right)$. 


\begin{tabular}{llll}
\hline Fuel & Coal & Oil & Gas \\
\hline Species & Composition [wt.\%] & & Composition [vol.\%] \\
\hline $\mathrm{C}$ & 89.0 & 87,5 & --- \\
\hline $\mathrm{H}_{2}$ & 5.0 & 11 & 0,4 \\
\hline $\mathrm{S}$ & 1 & 0,8 & --- \\
\hline $\mathrm{N}_{2}$ & 3 & 0,5 & 2,5 \\
\hline $\mathrm{CO}_{2}$ & -- & --- & 1,6 \\
\hline $\mathrm{CH}_{4}$ & --- & --- & 95.5 \\
\hline $\mathrm{SiO}_{2}$ & 2 & --- & --- \\
\hline
\end{tabular}

Table 2. Composition of coal, oil and gas applied for calculation.

The content of $\mathrm{SrO}$ was recalculated to $\mathrm{SrCO}_{3}$ via the multiplication by $\mathrm{M}_{\mathrm{SrCO}} / \mathrm{M}_{\mathrm{SrO}}$ ratio (147.63/ $103.62=1.42$ ). Other admixtures are neglected and the raw mixture composition is recalculated to $100 \%$ as is shown in Table 1 . The composition of coal is given by Table 2 .

Assuming the composition mentioned above, the raw material feed of 100 tons per hour, coal used as a fuel to keep the process temperature of $1250{ }^{\circ} \mathrm{C}$ and the content of strontium aluminate in clinker at least $90 \%$, the calculated material and energetic balance of furnace can be seen from Fig.2.
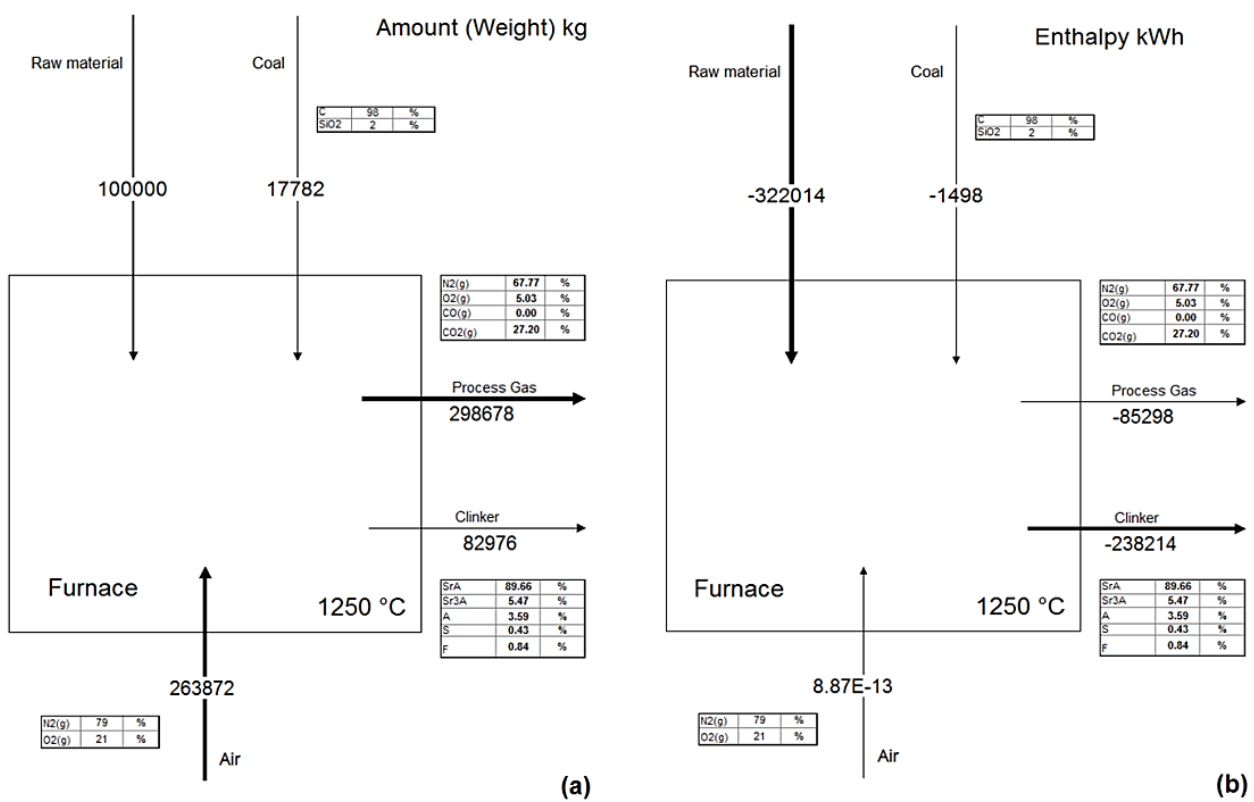

Figure 2. An example materials (a) and enthalpy balance (b) for the strontium aluminate clinker preparation process. 
The presence of silica in raw materials or coal used as the fuel may lead to the formation of mullite and strontium bearing feldspar ${ }^{3}$. Both are non-reactive temperature stable compounds without hydraulic behaviour but may serve as microfiller. The reaction of the process which takes place during the calcination of strontium aluminate clinker is discussed in Chapter 4.

Using oil or gas (Table 2) under the same conditions and kiln charge leads to the enthalpy balance shown in Fig.3.
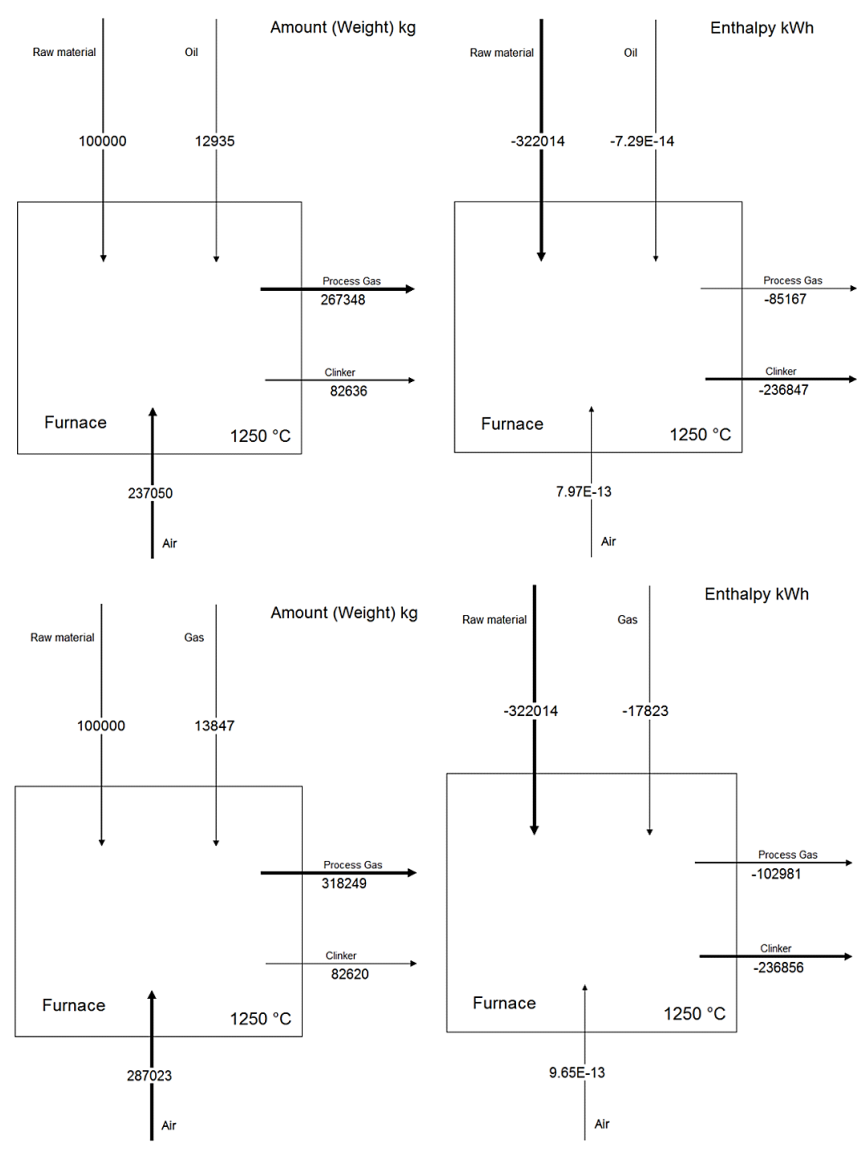

Figure 3. Preparation of strontium aluminate clinker using oil and gas as the fuel.

3 These feldspars have general composition given by formula $\mathrm{Me}^{2+} \mathrm{Al}_{2} \mathrm{Si}_{2} \mathrm{O}_{8}$, where $\mathrm{Me}^{2+}=\mathrm{Ca}^{2+}, \mathrm{Sr}^{2+}$ and $\mathrm{Ba}^{2+}$. Calcium, strontium and barium bearing feldspars are known as minerals anorthite, slawsonite ( $(\mathrm{Sr}, \mathrm{Ca}) \mathrm{Al}_{2} \mathrm{Si}_{2} \mathrm{O}_{8}$, sometimes termed as Sr-celsian $[893,901])$ and celsian, respectively. The crystallization of celsian is studied for the preparation of celsian ceramics and glass ceramics $[893,895,901]$. The formation of celsian was observed by Rezaie at al [15] after the addition of $10 \%$ colloidal silica or kaolin to barium aluminate cement. Regardless the source, the addition of $\mathrm{SiO}_{2}$ increases the setting time, improves workability and mechanical properties. 
Based on the discussion in Chapter 6.1.5, heating to the temperature interval of recrystallization of SrA phase $\left(1300-1400^{\circ} \mathrm{C}\right)$ seems to be the optimal conditions for the processing of strontium aluminate clinker. The formation of large crystals due to increasing temperature of thermal treatment over $1400{ }^{\circ} \mathrm{C}$ is undesirable since the reactivity of strontium aluminate clinker decreases and the cost of production increases. The sintering and formation of glassy phase at the temperatures over $1450^{\circ} \mathrm{C}$ (Chapter 4.3.3) increase the demands on grinding of calcinate (Chapter 3.5).

\section{Cooling of clinker}

Hot solids from the kiln are discharged on the grate of clinker cooler. As the grate moves with uniform speed along the cooler length, the solids lose their heat in cross-flow air. First part of air is generally sent to the kiln as secondary air, second part to calciner as tertiary air and third part is vented to the surroundings (vent air). The clinker comes out of the rotary kiln having high temperature of $1380^{\circ} \mathrm{C}$ and is cooled by fresh incoming air to the temperature of $65^{\circ} \mathrm{C}$ [297,299].

The clinker cooler serves for two purposes [298]:

i. Supplies the kiln with desired quantity of secondary air at correct pressure and temperature.

ii. Fast cooling the clinker to prevent any further reactions, and far enough to permit further handling.

The effect of OPC cooling rate on the fluidity of mortars was investigated by Nakano at al. [309]. The $\mathrm{C}_{4} \mathrm{AF}$ crystallite size calculated by the Rietveld method can be used to measure the cooling rate of clinker and to predict the fluidity of mortar. The fluidity of mortar increased with increasing cooling rate and with decreasing $\mathrm{C}_{3} \mathrm{~A}$ content. In slowly cooled clinker the calcium aluminoferrite phase is definitely lower in amount and $\mathrm{Al}_{2} \mathrm{O}_{3} / \mathrm{Fe}_{2} \mathrm{O}_{3}$ ratio than in rapidly cooled clinker [310]. Fast cooling rate results in the higher hydraulic reactivity of cement and reduce the setting time of cement slurry [1010].

\section{Grinding of clinker}

Rotary kilns produce an intermediate product called "clinker." Clinker is ground to produce cement [311]. More finely ground cement has larger specific surface and the reactive area available for the reaction with water is thus larger. The contact between surfaces of fine additives and sand is improved as well, the initial hydration of clinker minerals is made easier, and the distribution of hydration products is accelerated. It is recommended to keep the particle fineness expressed by the specific surface in the range of $2150-2400 \mathrm{~cm}^{2} \mathrm{~g} \mathrm{~g}^{-1}$ if we want to reach the optimal cement properties. Small addition of gypsum or anhydrite retards the start of cement sludge setting [312-315]. 
The procedure is divided into two sequential phases; crushing of lumps (3-25 mm) into loosely connected wafers in a dry roller press and subsequent fine milling of pre-processed clinker wafers in a rotating ball mill [316].

As was mentioned above, the ball mill is commonly used for fine milling of cement clinkers. The type of grinding media exerts significant influence on milling performance in terms of the product size and energy consumption. Various shapes of grinding media including rods, pebbles, and cylinders are used as an alternative to balls. The cylinders received particular attention because they have a greater surface area and higher bulk density than balls of similar mass and size [317-320].

Grinding of clinker represents energetically demanding part of the production process, which consumes about one-third of energy needed to produce cement. The production of fine ground clinker requires grinding stabilizers (grinding activators) which prevent the clinker from reagglomeration. Such additives, which are well known in both dry grinding and wet grinding processes, help decrease the enormous energy consumption of cement production [285,313,321].

For most of the twentieth century, the dry grinding circuits for the production of finished cement from cement clinker which consist of two-compartment tube mills and air separators, have been used. It is not uncommon to produce cement in an open circuit. The advances in cement grinding technology are slow and limited to more developed countries. Approximately $95 \%$ of feed to the cement grinding circuit are clinker and the rest of feed are "additives" which include grinding aids. The quality of cement is measured by the surface area or the Blaine index. The unit of the Blaine index is $\mathrm{m}^{2} / \mathrm{kg}$, and this index is determined by the Blaine air permeability test. In the past 20 years, high pressure grinding roll (HPGR) technology has been used in pre-crushing the clinker. Presently, many American and European cement grinding circuits have HPGR which increases the grinding capacity and energy efficiency [279].

The effectiveness of seven grinding aids, namely triethanolamine, mono-and diethylene glycols, oleic acid, sodium oleate, sulphite waste liquor and dodecylbenzene sulphonic acid on the batch grinding of Portland cement clinker, limestone and quartz was investigated in a laboratory ball mill by Sohoni at al. [322]. While the grinding aids had only a marginal effect on grinding of quartz, they had significantly beneficial effect on the grinding of limestone and cement clinker. Triethanolamine appeared to be the most effective of all aids studied. In grinding of cement clinker, gypsum also acted as very effective grinding aid. The action of these additives was attributed to their ability to prevent the agglomeration and balls and mill from coating by powder.

The presence of easily ground limestone leads to a wider particle size distribution of mixture. Limestone is concentrated in fine fractions $(<8 \mu \mathrm{m})$ while the clinker is concentrated in coarser ones. However, limestone content over $30 \%$ obstructs the grinding of both clinker and limestone [323].

Also calcinate formed during the processing of strontium aluminate clinker must be finely ground in order to prepare the strontium aluminate cement. The increase in specific surface area improves the reactivity of binder with water. Moreover, the admixtures such as cal- 
cined bauxite and alumina can be introduced into the clinker. These mineral admixtures serve as micro-fillers, similarly to calcite ${ }^{4}$ milled with clinker during the preparation of Portland cement $[315,320,323,324]$. The grinding kinetics, the effect of grinding media and the additives were already described in Chapter 2.7.

4 The use of Portland limestone cements has many benefits, both technical and economical. The European Prestandard prEN 197-1 identifies two types of Portland limestone cement containing 6-20\% limestone and 21-35\% limestone, respectively [320]. 
